\title{
Gold in Thick Film Hybrid Microelectronics
}

\author{
R. G. Finch
}

The Electrical Research Association, Leatherhead, Surrey, England

\begin{abstract}
For a number of years microelectronic components have been made by screen printing patterns of resistive, conductive, insulating and dielectric pastes on to ceramic wafers and firing these in air to temperatures between 700 and $1000^{\circ} \mathrm{C}$. Such thick film microcircuits are relatively inexpensive to make and offer a wide range of camponent values with good stable electrical properties. They have, therefore, found wide acceptance in industry and a substantial and increasing volume of thick film circuits is now being made.
\end{abstract}

In the production of microelectronic components by the thick film process the pastes used to screen print the required patterns consist of inorganic powders suspended in an organic medium. After the patterns have been printed, the solvents are evaporated from the wet prints and the remaining organic constituents are removed by combustion in air during the early stages of the firing cycle used to mature the film. The firing process thus leaves a purely inorganic film which has been fused to the ceramic wafer to provide a hard, adherent and abrasion-resistant component.

The selection of the inorganic materials used in these pastes is dictated mainly by the electrical properties demanded of the fired film. Screenprintable pastes that are used to provide insulating layers between successive conductor planes utilise devitrifiable glasses, whereas a mixture of fusible oxides or fusible glasses and ferro-electric crystals such as barium titanate is used to provide the dielectric layer for film capacitors. The noble metal semiconducting oxides, such as palladium oxide, ruthenium dioxide and iridium dioxide are used with glass powders to provide resistive films; and noble metal powders (gold, platinum, palladium or silver) are used mixed with relatively minor amounts of glass powders to provide conductor films.
These conductor films find application in thick film microelectronics not only to provide printed wiring, but also to provide resistor terminations, capacitor electrodes, and solderable, weldable or brazeable pads to facilitate the packaging and assembly of the microcircuit.

The properties that may be demanded of thick film conductor glazes are that:

(i) the films can be generated in precisely oriented and finely defined patterns capable of resolving lines of 100 micron width on 200 micron centres. The ability to resolve fine pattern detail is mainly a property of the organic vehicle used to suspend the powders, but it is also influenced by the particle morphology of the powders used. Gold powders, for example, when present in particle sizes greater than 5 micron, tend to deform into laminar flakes during the operation of pigment dispersion. The flaked gold can block the screen and lead to poor pattern definition.

(ii) the films are capable of being fired in air to temperatures between 700 and $1000^{\circ} \mathrm{C}$. In addition the fired films may also have to withstand exposure to reducing atmospheres of 15 per cent hydrogen, 85 per cent nitrogen at temperatures of up to $500^{\circ} \mathrm{C}$, for several minutes during brazing operations. This obviously introduces the additional requirement that the glass powders used in these compositions are not reducible under these conditions.

(iii) the sheet resistivity* of the fired film should not exceed $100 \mathrm{~m} \mathrm{ohm} / \mathrm{sq}$. This requirement limits the range of palladium and platinum gold alloys that are suitable for these applications, as will be discussed in detail later. In addition many applications require sheet resistivities of less than $10 \mathrm{~m} \mathrm{ohm} / \mathrm{sq}$. The attainment of these very low resistivities demands the use of pure gold as the sole conducting species and rules out the use of alloys.

* Sheet resistivity is defined as the resistance in ohms of a unit square film. This parameter is independent of the lateral dimensions of the square but is inversely proportional to the thickness. By convention
sheet resistivities are quoted normalised to a film thickness of 0.001 inch (25 microns). 
Sereen printed and fired multi-layer gold conluctors manufactured by Welwyn Electric Limited. The upper pair of circuits shows the first pattern of gold conductors; the lower pair shows the completed interconnection circuits in which the second visible patterns of conductors are separated from the first by a screen printel and fired insulating layer. These completed circuits are ready to accept discrete components mounted by suitable bonding techniques

(iv) the fired film should form ohmic junctions with printed and fired thick film resistors. Ideally this involyes a limited and controlled amount of interdiffusion taking place between the resistor and conductor films during the firing cycle. Unalloyed gold compositions are not widely used; palladium-gold and platinum-gold compositions are more favoured for this application.

(v) the fired film should possess a surface of metallic character, such that discrete silicon or germanium devices can be mounted by eutectic die bonding; such that wire bonds can be made by thermo-compression bonding of gold wire or by ultrasonic bonding of aluminium wire; and such that lead frames, wires and discrete components can be attached by soldering techniques or by brazing.

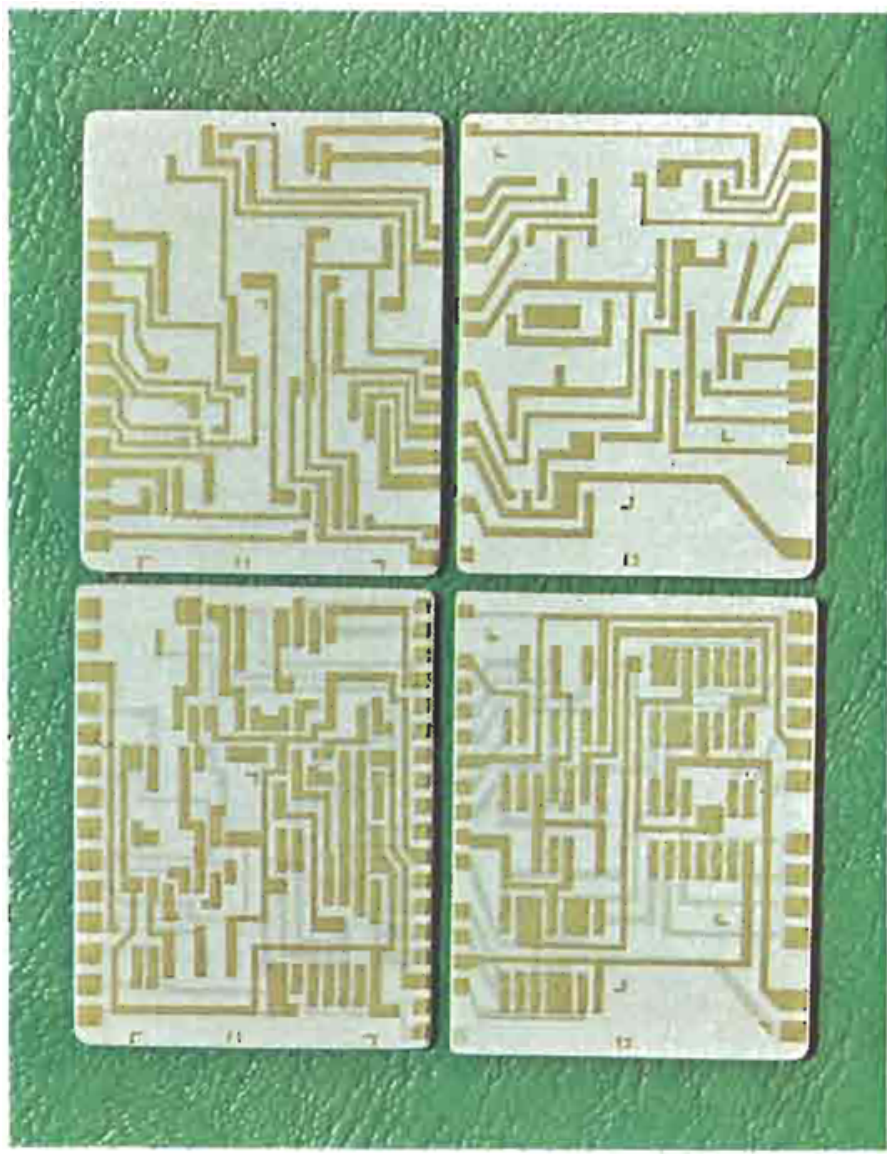

(vi) the fired film should be tightly adherent to the underlaying ceramic wafer.

(vii) the fired film should not suffer undue degradation of these properties on exposure to unfavourable conditions of heat and humidity.

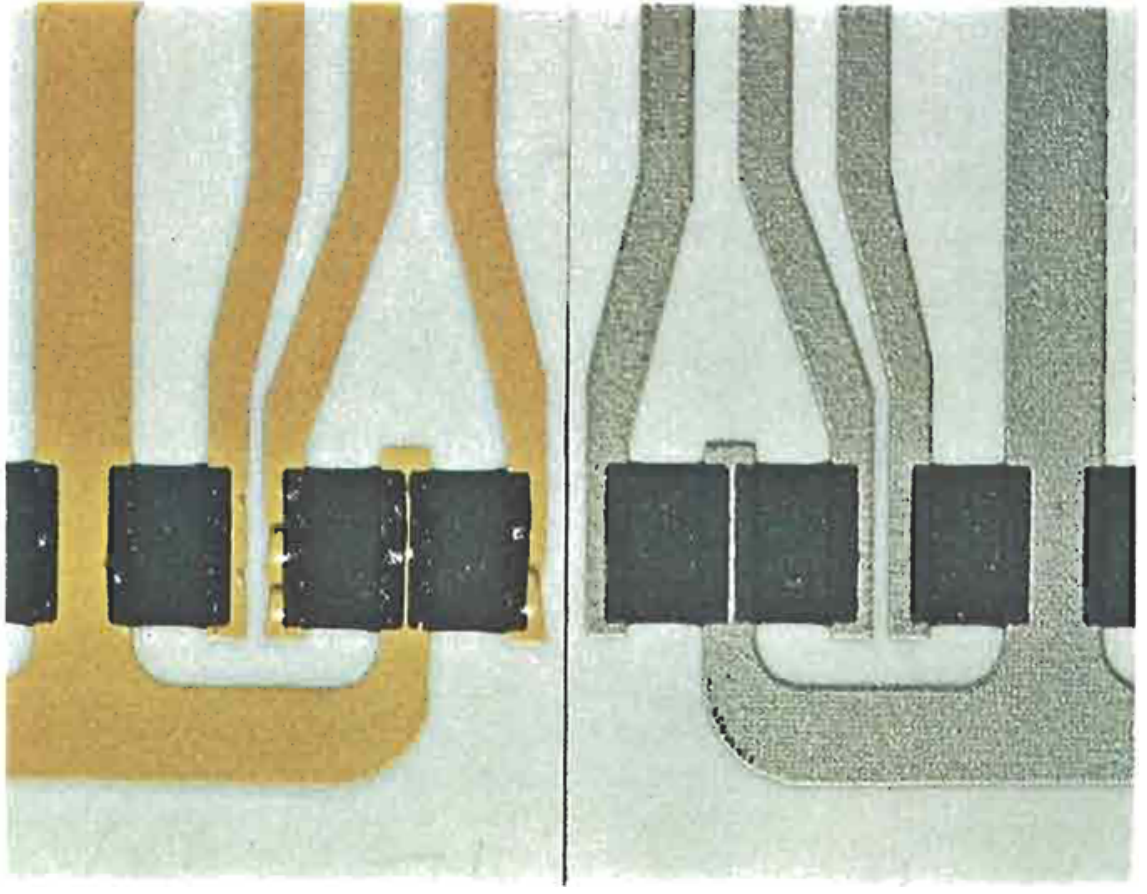

While unalloyed gold compositions are used for conductor networks, where resistors must be incorporated in a circuit, alloyed gold preparations are preferred in order to avoid interdiffusion between the resistor and conductor films during firing. Signs of resistor-conductor incompatibility can be seen in the enlarged view of the gold conductor on the left. These junctions show bubbles, while the platinum-gold conductor on the right, fired with the same resistor composition, is free from bubbles at the junction 


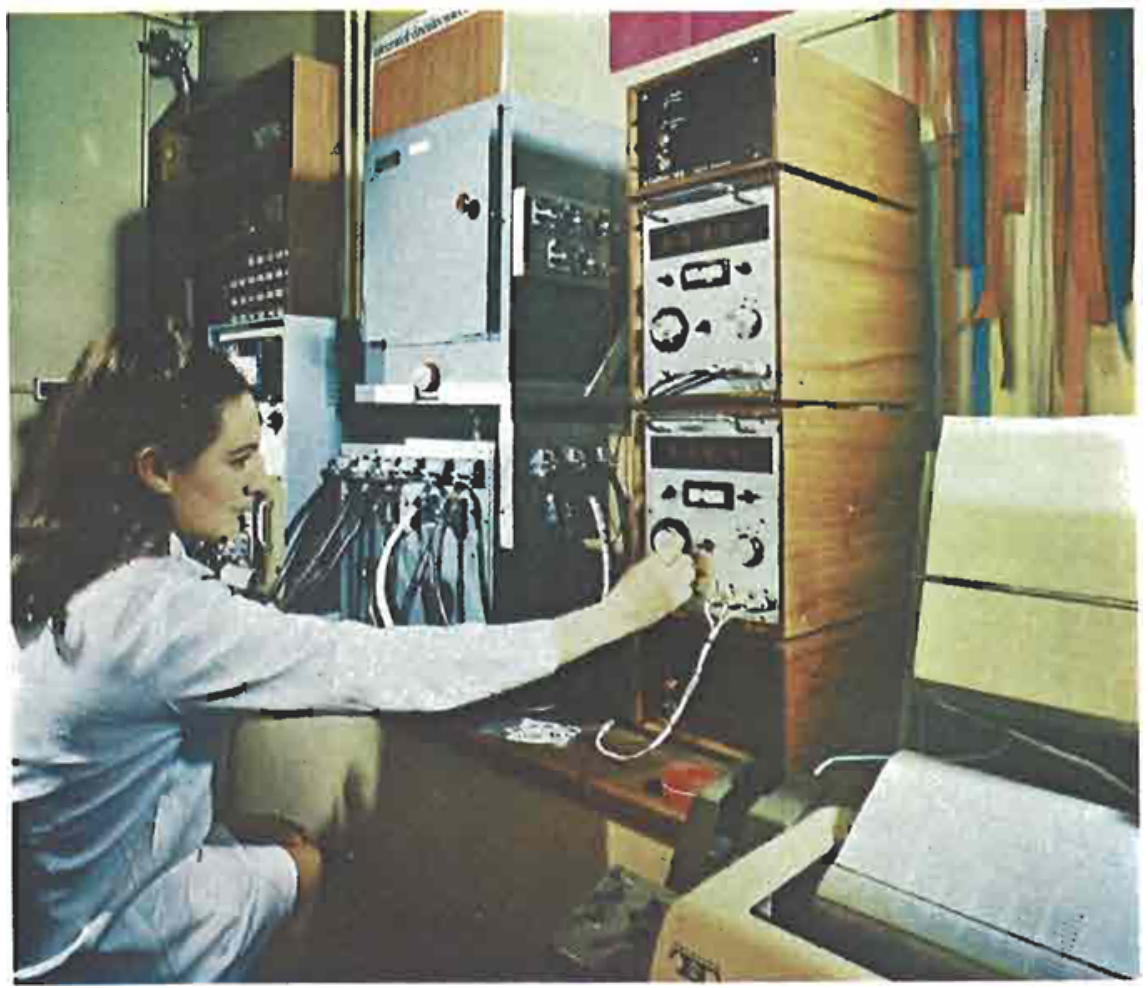

A number of proprietary goldhased silk screening preparations, each designed to meet specific requirements, are $110 \mathrm{w}$ available from companies engaged in this type of work. In producing these preparations it is necessary to have a rapid means of measuring their cluaracteristics after firing and this illustration shows perfornance data being establisher in a Jolmson Matthey laboratory, using an automatic component bridge, digital serialiser and teleprinter installation

No one conductor formulation offers all these properties, but a large number of proprietary formulations have been developed to meet specific requirements. Most of these are based on gold, or platinum and gold mixtures, or palladium and gold mixtures, as the conducting species; in addition one widely used material is based on palladium-silver. The table shows some typical formulations of goldcontaining conductor pastes.

In formulating these compositions the metal is usually prepared as a chemically precipitated powder to achieve the required small particle size. Dispersion of these powders with finely divided glass into an organic screening vehicle is easily achieved by conventional techniques such as triple roll milling.

The first formulation given in the table is a

\begin{tabular}{|c|c|c|c|}
\hline & 1 & II & III \\
\hline Gold (1 micron powder) & 80.0 & 70.0 & 66.0 \\
\hline $\begin{array}{l}\text { Platinum } \\
\qquad(0.1 \text { micron powder })\end{array}$ & - & 10.5 & - \\
\hline $\begin{array}{l}\text { Palladium } \\
\text { (0.2 micron powder) }\end{array}$ & - & 一 & 12.0 \\
\hline $\begin{array}{l}\text { Inorganic binder } \\
\qquad(5 \text { micron powder) }\end{array}$ & 20.0 & 19.5 & 22.0 \\
\hline & 100.0 & 100.0 & 100.0 \\
\hline
\end{tabular}

typical composition of a gold-based conductor in which the percentage of gold used can be varied between approximately 70 and 95 per cent by weight. One application in which a 95 per cent by weight gold conductor would be used is to provide eutectic die bonding areas upon which silicon dice can be mounted by ultrasonic eutectic bonding. In this operation bonding of the die to the film occurs via the formation of the gold-silicon eutectic alloy and this may be accomplished by heating the substrate bearing the fired gold film to 370 to $390^{\circ} \mathrm{C}$ under an inert atmosphere. At the same time the silicon die is ultrasonically vibrated under a load in contact with the fired film. The gold-rich surface of the fired film interacts under these stresses with silicon to form the low melting gold-silicon eutectic. A careful control must be exercised over the time the goldsilicon interface is exposed to these temperatures to prevent excessive dissolution of the silicon in the gold. These compositions are also noted for their ability to accept ultrasonic aluminium wire bonds at room temperature and to form thermo-compression bonds with gold wire at a substrate temperature of approximately $310^{\circ} \mathrm{C}$.

Gold compositions can also be formulated to provide printed and fired areas on a ceramic based circuit on to which Kovar lead frames can be attached by brazing. Since brazing is carried out in a reducing atmosphere ( 15 per cent hydrogen, 85 per cent nitrogen) proper attention must be given to the chemical nature of the glasses being employed as 
fluxes in these compositions. In order to braze gold conductive films the eutectic brazing alloys, goldgermanium (brazing temperature range 450 to $600^{\circ} \mathrm{C}$ ) and gold-tin (brazing temperature range 325 to $400^{\circ} \mathrm{C}$ ) are used as preforms between the Kovar lead frames and the printed and fired gold pad. Due to the ready solubility of the printed and fired gold film in the molten gold-tin or gold-germanium alloys, the brazing times must be kept short and well controlled. Gold conductor films are therefore used not only where the highest conductivity is demanded but also where metallurgical bonding operations are required to interconnect and package the circuit. However, their use is limited by the fact that gold conductor films are not widely compatible with thick film resistors and that gold conductor films cannot easily be soldered by the readily available tin-lead solders due to scavenging of the gold by the molten alloy.

Although some attempts have been made to provide solderable gold conductors by restricting the gold content of the fired film to a critical concentration, the platinum-gold and palladium-gold conductors are more widely used where a solderable conductive path is required or where the conductors are used to terminate thick film resistors.

Formulation II in the table outlines a typical palladium-gold formulation (U.S. Patent 3,440,062) which is a specific example of a range of possible palladium-gold formulations. This particular formulation offers excellent solderability with a considerable resistance to scavenging of the metal film by the molten solder alloys. The fired film will tolerate an immersion of 120 seconds in molten $60 / 40$ tin/lead solder at $215^{\circ} \mathrm{C}$, without apparent loss of printed area.

The sheet resistivity of this formulation is approximately $40 \mathrm{~m} \mathrm{ohm} / \mathrm{sq}$. and it is fully compatible with resistor glazes. The adhesion of the fired film to the substrate can vary from 900 to over $2000 \mathrm{lb} / \mathrm{in}^{2}$ depending on the chemical nature of the glass powder used as the organic binder.

The diagram shows a general relationship between the composition of the film and the properties of adhesion, solderability and sheet resistivity. The data on which this diagram is based are drawn from a number of patents held by E. I. du Pont de Nemours and the comments that follow apply largely to compositions based upon their technology.

It can be seen that the sheet resistivity increases as the percentage of gold in the film decreases, that adhesion increases as the percentage of glass increases, and that solderability is only achieved over a restricted compositional range. Highly conductive solderable films with satisfactory adhesion can be obtained with a 20 per cent glass, 74 per cent gold and 6 per cent palladium composition. If, however, a conductor film with maximum adhesion is required,

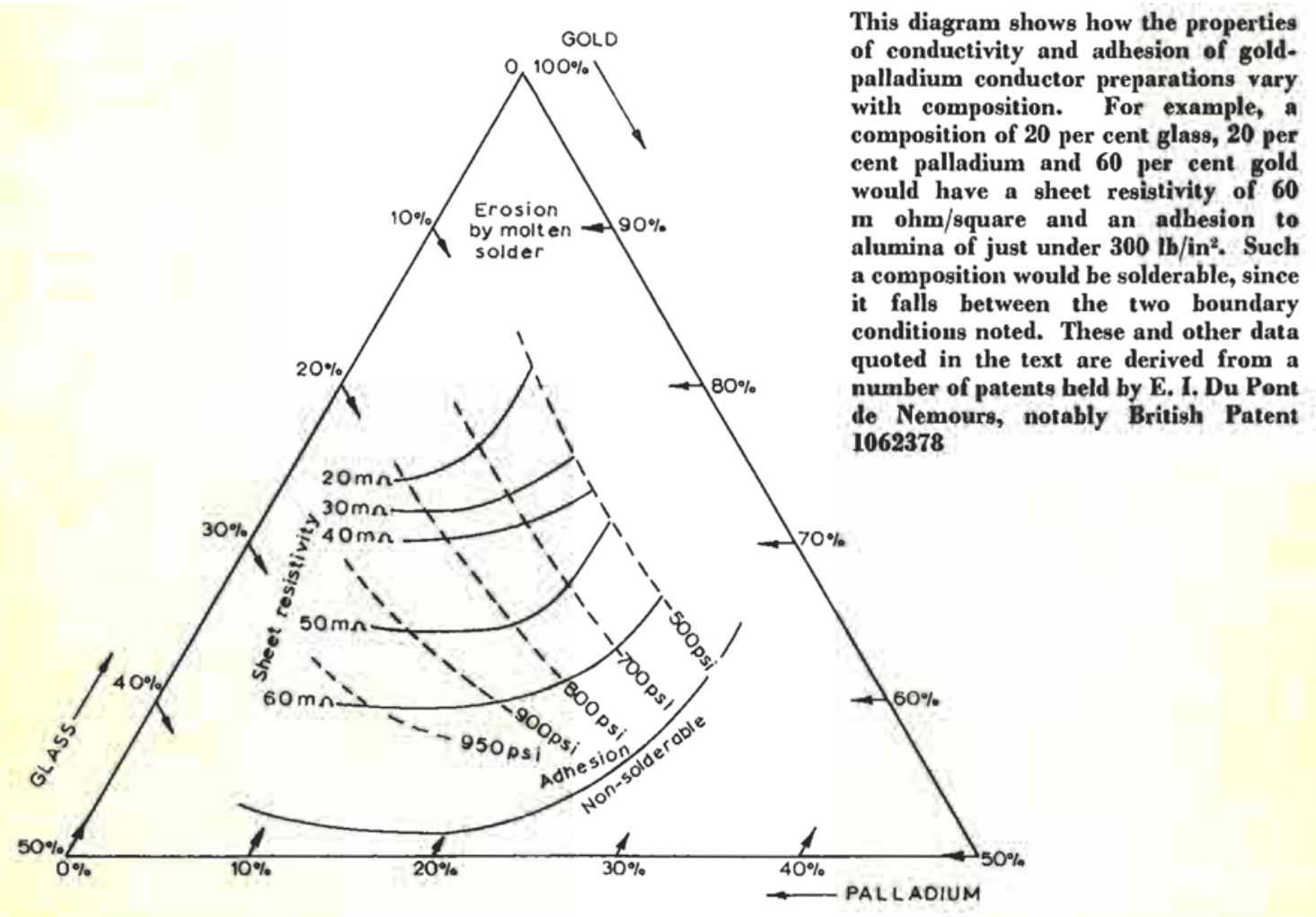






A screen printed and fired gold conductor network on which are mounted discrete silicon semiconductor components, The connections from the gold cireuit to the terminals on the silieon elips have heen made by thermo. compression bonding with fine gold wires

yet one which still retains solderability, then a composition of 29 per cent glass, 60 per cent gold and 11 per cent palladium may be selected.

Similar compositional diagrams can also be constructed for the glass-gold-platinum system. These compositions by and large have very similar properties to the glass-gold-palladium compositions and also exhibit excellent solderability, good compatibility with thick film resistors and high adherence to the substrate.

Both platinum-gold and palladium-gold glass conductor films can accept thermo-compression and ultrasonic wire bonds with gold and aluminium wire respectively but require higher bonding temperatures or longer power time cycles than conductor films based on gold as the sole conducting species.

Apart from the binary alloy formations discussed above two ternary alloy compositions have been developed to rectify some deficiencies noted in certain binary alloy compositions.

Platinum-gold formulations show a tendency to craze and fissure under some firing conditions. This behaviour has been associated with the very small particle size of the metals ( 0.1 to 1.0 micron) used, leading to large volume changes on sintering. Attempts to rectify this defect $(a)$ by increasing the particle size of the platinum or $(b)$ by increasing the particle size of the gold leads to increased erosion of the printed and fired film in a solder bath. The obvious solution of increasing both the platinum content and the particle size of the platinum is unattractive on cost considerations. An acceptable formulation can be found by reducing the gold content of the platinum-gold formulation and substituting palladium of a rather coarse particle size. A composition containing 54.4 per cent gold, 18.3 per cent platinum and 18.3 per cent palladium with 9.0 per cent inorganic binder has been found to give solderable craze-free fired conductor films that are compatible with thick film resistors. This composition has been found to give particularly dense and craze free lands on firing at $950^{\circ} \mathrm{C}$, but its particular merit is that it is wetted by molten solder with outstanding ease and yet shows no sign of erosion of the fired film.

The second ternary alloy that has been developed arises from the known tendency of palladium-silver conductor films to exhibit silver migration under the influence of applied voltages in humid conditions. Conductors based on silver alone migrate under a stress of a few volts within seconds when wet with deionised water; conductors based on silver-palladium alloys migrate under the same field but over a time scale an order greater. The addition of gold to this binary alloy appears to suppress this phenomenon of silver migration entirely while at the same time providing a conductor composition which is relatively inexpensive. A composition of 55 parts of gold to 20 parts of silver and 25 parts of palladium with 8.5 per cent inorganic binder (based on the total metal content) is claimed to be particularly resistant to silver migration and is cheaper than the competitive platinum- and palladium-gold compositions.

The author wishes to thank the Assistant Director Technical of the Electrical Research Association for permission to publish this article. 